\title{
The Role of Role Uncertainty in Modified Dictator Games*
}

\author{
Nagore Iriberri ${ }^{+}$ \\ Universitat Pompeu Fabra
}

\author{
Pedro Rey-Biel ${ }^{* *}$ \\ Universitat Autònoma de Barcelona
}

First Draft: May 12, 2008

This Version: April 29, 2010

\begin{abstract}
We compare behavior in modified dictator games with and without role uncertainty. Subjects choose between a selfish action, a costly surplus creating action (altruistic behavior) and a costly surplus destroying action (spiteful behavior). While costly surplus creating actions are the most frequent under role uncertainty $(64 \%)$, selfish actions become the most frequent without role uncertainty (69\%). Also, the frequency of surplus destroying choices is negligible with role uncertainty (1\%) but not so without it $(11 \%)$. A classification of subjects into four different types of interdependent preferences (Selfish, Social Welfare maximizing, Inequity Averse and Competitive) shows that the use of role uncertainty overestimates the prevalence of Social Welfare maximizing preferences in the subject population (from $74 \%$ with role uncertainty to $21 \%$ without it) and underestimates Selfish and Inequity Averse preferences. An additional treatment, in which subjects undertake an understanding test before participating in the experiment with role uncertainty, shows that the vast majority of subjects (93\%) correctly understand the payoff mechanism with role uncertainty, but yet surplus creating actions were most frequent. Our results warn against the use of role uncertainty in experiments that aim to measure the prevalence of interdependent preferences.
\end{abstract}

Keywords: role uncertainty, role reversal, interdependent preferences, social welfare maximizing, inequity aversion, mixture-of-types models, strategy method, experiments.

JEL classification: C72; C91; D81.

\footnotetext{
* We thank Miguel A. Ballester, Gary Charness, Rosemarie Nagel, Joel Sobel and Carmit Segal for their comments. We would like to also thank anonymous referees for their corrections, comments and suggestions. We are grateful to Aniol Llorente-Saguer, Natalia Montinari for their help in running the experiments. Nagore Iriberri acknowledges financial support from Fundación Rafael del Pino, Ministerio de Educación y Ciencia (ECO2009-11213 and SEJ2007-64340) and the support of the Barcelona GSE Research Network and the Government of Catalonia. Pedro Rey-Biel acknowledges financial support from Ministerio de Ciencia y Tecnologia (ECON2009-0716 and Consolider-Ingenio CSD2006-00016) and the Barcelona GSE Research Network and of the Government of Catalonia (2009SGR-00169).

+ Nagore Iriberri. Departament d'Economia i Empresa. Universitat Pompeu Fabra, Ramón Trías Fargas 25-27, 08005 Barcelona (Spain). Tel: (+34) 9354226 90. E-mail: nagore.iriberri@upf.edu.

** Pedro Rey-Biel. Universitat Autònoma de Barcelona. Department d'Economia i d'Historia Econòmica. 08193, Bellaterra. Barcelona (Spain). Tel: (+34) 935812113. E-mail: pedro.rey@uab.es.
} 


\section{Introduction}

Role uncertainty is a commonly used experimental procedure. It consists of collecting from the same subject responses to tasks assigned to different roles, and letting a random mechanism determine which role's actions will be implemented and used for payment. Two main advantages can be highlighted. First, it increases the information obtained from a given sample size of subjects. Second, it may facilitate the understanding of the payoff structure, and thus strategic thinking in games, since subjects are asked to play under different roles. The justification behind its widespread use is that according to the standard game-theoretic view subjects' behaviour should not be affected.

Engelmann and Strobel (2004) understand role uncertainty as a reduced form of the strategy method (Selten, 1967) for normal form games. The strategy method is commonly used in sequential games to elicit responders' choices to all possible decision nodes. Roth (1995) argued that this method transforms a sequential game into a normal form game and suggested future experiments to determine when/if the strategy method may produce differences in observed behaviour. See Brandts and Charness (2009) for a comprehensive review on the comparison of behaviour when the strategy and the direct methods are used.

In simple distribution experiments designed to identify and quantify interdependent preferences, such as the Dictator Game, role uncertainty is one available methodological option. ${ }^{1}$ A distribution experiment requires at least two roles: a "Dictator" ("Decider" in our experiment), who decides an allocation of payoffs, and a "Receiver" who has no active role and simply gets paid according to the allocation proposed by the Decider. There are three ways in which these experiments are usually implemented. First, with role certainty, subjects are assigned specific player roles before decisions are made. Notice that no behaviour is elicited from half of the subjects despite being paid, which is seen in occasions as a waste of resources. Second, using role reversal, subjects play in both roles, once as a Dictator and once as a Receiver, and decisions in both roles are implemented and used for payment. ${ }^{2}$ This method could lead to endowment effects stemming from expectations of what other subjects may have chosen. Third, role

\footnotetext{
1 "Social preferences" and "other-regarding preferences" have been used to refer to distributional preferences as well as reciprocity concerns. Since our setting is non-strategic we focus on purely distributional preferences and thus use the term "interdependent preferences" to refer to purely distributional concerns. See also Fisman et al. (2007) for a discussion on the difference between preferences for giving and social preferences.

${ }^{2}$ See for example Charness and Rabin (2002), Andreoni and Miller (2002), Andreoni et al. (2003), Burks (2003) and Fisman et al. (2007).
} 
uncertainty, described above, offers a cost saving method without any endowment effect problem. $^{3}$

This paper aims to compare individual behaviour in simple modified dictator games with and without role uncertainty. We use modified dictator games where Deciders choose among three available actions, a selfish action, a surplus creating action (altruistic behaviour) and a surplus destroying action (spiteful behaviour). Altruistic and spiteful behaviour comes at a cost for the Decider. Our initial sessions used role uncertainty to increase information acquisition. However, the strong prevalence of costly altruistic behavior drew our attention. This led us to question the use of role uncertainty and motivated this study, which aims to document the comparison of making distributional choices with role uncertainty (RU) and with role certainty (RC).

The distribution of choices changes dramatically depending on whether role uncertainty is used or not. While the surplus creating action, consistent with altruistic behaviour, is the most frequently chosen action in the treatment with role uncertainty (64\%), the selfish action becomes the most frequently chosen without role uncertainty $(69 \%)$. Also, the frequency of surplus destroying choices, consistent with spiteful behaviour, is negligible with role uncertainty $(1 \%)$ but not so with role certainty (8\%).

We carry out a within subject analysis to classify subjects into four different interdependent preferences-types: Selfish, Social Welfare Maximizing, Inequity Averse and Competitive preferences. ${ }^{4}$ We show that the use of role uncertainty clearly affects the preferences-type distribution in-line with the distribution of actions mentioned above. The majority of subjects $(74 \%)$ are estimated to be Social Welfare maximizers with role uncertainty, but without it, the majority of subjects are estimated to be Selfish (44\%), while Social Welfare maximizers' frequency decreases to $21 \%$. Also, the proportion of Inequity Averse individuals is small with role uncertainty (5\%) but it increases to $25 \%$ without it.

\footnotetext{
${ }^{3}$ See, for example, Charness and Grosskopf (2001) in their Study 2 and Engelmann and Strobel (2004).

${ }^{4}$ Charness and Rabin (2002) propose a utility function that includes all these types of interdependent preferences. We refer to the model presented on page 822 in their paper, where parameter $q$ is set to be equal to zero (no reciprocity issues considered). Thus, there are only two relevant parameters in the model, $\rho$ and $\sigma$, the weights for others' payoffs when ahead and behind respectively. Selfish preferences assume both $\rho$ and $\sigma$ are equal to zero. Social Welfare maximizing preferences assume these two weights are strictly positive. It should be noted that our Social Welfare maximizer type is not based on the more general Social Welfare maximizer model depicted in their Appendix, in which there exists a trade-off between the total surplus and the payoff of the individual who is worst-off. Charness and Grosskopf (2001) find that this more complicated Social Welfare maximizer represents individuals' preferences better. Inequity Averse preferences assume $\rho$ is strictly positive while $\sigma$ is strictly negative and finally Competitive preferences assume both $\rho$ and $\sigma$ are strictly negative.
} 
The use of role uncertainty may add an element of complication in the understanding of experimental instructions affecting subjects' choices. In particular, subjects may not fully understand the fact that only actions taken in the randomly determined role will matter, confusing role uncertainty with making choices under the veil of ignorance. Note that role uncertainty in the modified dictator games is definitely different from making choices under the veil of ignorance. This normative concept was introduced by Harsanyi (1953) and Rawls (1971) to describe distributional choices before a decider knows the realization of a "state of nature" referring to its position in a welfare distribution (poor or rich). The difference is that while under the veil of ignorance the uncertainty is about the position in a welfare distribution, under role uncertainty the uncertainty is about the capacity of deciding. Under the veil of ignorance, once the position in a welfare distribution is known, the distribution chosen by a subject is always implemented. However, under role uncertainty, once the roles are randomly assigned, a subject finds out whether her choice will be implemented or not. ${ }^{5}$ However, subjects may not anticipate that in the case their randomly assigned role is that of the Receiver, their own allocation for the Receiver is not implemented but some other player's allocation is used to determine Receiver's payments. In fact, in the role uncertainty treatment a common answer to an ex-post experiment questionnaire in which subjects were asked to justify their choices read as follows: "Just in case I happened to be the Receiver, I chose the action that gave the highest total surplus". 6

This raised the question of whether the subjects fully understood the payoff mechanism under the use of role uncertainty. We therefore replicated our experiment with role uncertainty including an understanding test right after the instructions and before they proceeded to take their actions. We will refer to this treatment as RU+T. The vast majority of subjects, $93.4 \%$ (56 out of 60 subjects), passed the understanding test successfully. Moreover, the pattern in behaviour is similar to the behaviour under the role uncertainty treatment without the understanding test. The surplus creating action is the most frequent (56\%), followed by selfish action (40\%), while the surplus destroying action is negligible (4\%). With regard to the interdependent preferences type classification, we find a similar distribution to that of role uncertainty without the

\footnotetext{
${ }^{5}$ Bolton and Ockenfels (2006) conducted an experiment in which subjects vote for distributions under the veil of ignorance, i.e., not knowing their position in the welfare distribution. Results are used to reply to Engelman and Strobel (2004) critique that efficiency concerns may be more prevalent than inequality concerns, as modeled by Bolton and Ockenfels (2000). They find that choosing under the veil of ignorance and choosing when they know their relative position beforehand makes a difference.

${ }^{6} \mathrm{~A}$ translation of subjects' answers to questions 2 and 3 in the questionnaire (see Appendix) is available upon request.
} 
understanding test. The majority of subjects, $64 \%$ of them, are identified as behaving consistent with social welfare maximizing preferences, followed by selfish (20\%), inequity averse (14\%) and competitive preferences (2\%).

This paper contributes to the methodology of experiments by showing that the use of role uncertainty, compared to role certainty, can significantly change the observed prevalence of altruistic, selfish and spiteful behaviour in simple modified dictator games. Dictator game experiments have been regularly carried out using either role certainty or role reversal procedures. However, when the simple structure of the dictator game is modified in order to study more complex aspects of interdependent preferences, namely in "distributional" or "modified dictator" games, role uncertainty has been used. We are aware of two previous experimental studies which have used role uncertainty in modified dictator games, Charness and Grosskopf (2001) and Engelmann and Strobel (2004), to study issues related to the existence and quantification of interdependent preferences. Our study suggests that Charness and Grosskopf's (2001) and Engelmann and Strobel's (2004) results with respect to the prevalence of different interdependent preferences may be partly driven by the use of role uncertainty, although its implications are limited to a very low number of decision tables these authors use (1 out of 3 in Charness and Grosskopf, 2001, and 2 out of 11 in Engelmann and Strobel, 2004). Nevertheless our results should be interpreted as a cautionary tale for the use of role uncertainty in experiments which elicit interdependent preferences.

The paper is organized as follows. The second section describes the experimental design and procedures. The third section reports the results and discusses the implications for Charness and Grosskopf's (2001) and Engelmann and Strobel's (2004) results. Finally, in the last section, we conclude. We also include an appendix, section 6, which contains the instructions used for the experiments.

\section{Experimental Design and Procedures}

Ten experimental sessions were conducted in the Laboratori d'Economia Experimental (LEEX) at Universitat Pompeu Fabra using the Z-Tree experimental software (Fischbacher, 2007) in November 2007, February 2008 and April 2010. Instructions were handed out in Spanish. A total of 260 subjects, who had not participated in similar experiments in the past and who did not know what the experiment was about, were recruited using the ORSEE recruiting system (Greiner, 2004). In November 2007, we performed 4 sessions, with 20 subjects each, using role uncertainty (RU). In February 2008, we performed 3 sessions of 40 subjects each with 
role certainty (RC). In April 2010, we performed 3 sessions, with 20 subjects each, using role uncertainty and an understating test before subjects made their choices $(R U+T)$. Subjects in all experimental sessions were chosen from the same subject pool, according to the same selection criteria and guaranteeing that no subject participated in experiments with and without role uncertainty. See Figure 1 for a summary of different treatments. Apart from whether role uncertainty was used or not, and whether there was an understanding test, procedures and design in all treatments were the same, as explained below.

Figure 1. Summary of Treatments

\begin{tabular}{|c|c|c|c|}
\hline Date & $\begin{array}{c}\text { Number of Sessions } \\
\text { (Subject Number) }\end{array}$ & Method & $\begin{array}{c}\text { Total Number of Decisions } \\
\text { for Each Decision Table }\end{array}$ \\
\hline November 2007 & 4 (80 Subjects) & Role Uncertainty (RU) & 80 \\
\hline February 2008 & 3 (120 Subjects) & Role Certainty (RC) & 60 \\
\hline April 2010 & 3 (60 Subjects) & $\begin{array}{c}\text { Role Uncertainty with } \\
\text { Understanding Test (RU+T) }\end{array}$ & $\begin{array}{c}56 \text { passed the } \\
\text { understanding test }\end{array}$ \\
\hline
\end{tabular}

There are two player roles, "Decider" and "Receiver". Deciders make choices in sixteen different decision tables which affect both Deciders' and Receivers' payoffs. "Receivers" do not take any decision that can affect either the Receivers' or the Deciders' payoffs. In the RU and RU+T sessions, 20 subjects performed the task without knowing until the end of the experiment whether their role would be that of the Decider or the Receiver, which was randomly assigned by the computer. The exact sentences explaining the random assignment mechanism were as follows:

\footnotetext{
"The computer will also randomly choose whether you are the "Decider" or the "Receiver". That is, the computer will randomly choose if the option you have chosen in that particular table is implemented, so that you will be the "Decider" or, on the other hand, if the option chosen by the participant from your group with whom you are randomly matched in that particular table is implemented.
}

Please notice that chance uniquely determines whether your role will be "Decider" or "Receiver", once all participants have made their choices. Thus, the option you choose will only be taken into account if chance finally determines that for a particular table it is your option the one being implemented. In case in the chosen table your choice is not the one being implemented, your choice is simply not taken into account and no participant is informed of it.

Therefore, in case your choice is not being implemented, your choice can affect in no way your payment or the payments of any other participant". 
RU also included two examples that explained the payoff mechanism under role uncertainty; one example covered the case when the subjects happened to be the decider and one when the subject ended up being the receiver (see Instructions in the Appendix). RU+T, in addition to the two examples, included an understanding test where subjects had to fill in gaps that if correctly answered guaranteed the understanding of the payoff mechanism under role uncertainty. 56 out of 60 subjects successfully passed the test, showing that the vast majority of subjects, $93.4 \%$, understood the instructions with role uncertainty. Similarly, RC also included an example explaining the payoff mechanism (see Instructions in the Appendix).

In the RC sessions, 40 subjects were recruited and after arrival they extracted a piece of paper from a bag which randomly determined whether they would stay in the laboratory and play as Deciders, or they would go to a different classroom and play as Receivers. In the RU and RU+T sessions all subjects were in the same room. It is unlikely that differences in our results are due to physical separation since we used cubicles in all sessions, making visual contact among subjects almost impossible.

Experimental sessions in the RU and RC treatments lasted one and a half hours because the experiment contained three different tasks. Experimental sessions in the RU+T treatment lasted half an hour, since subjects only performed one task. The focus of this paper is on the first task, which all subjects performed in their respective experiments. The first part is totally independent of the rest of the tasks since subjects did not find out about the task in each part until that part was reached. The other two tasks in the RU and RC treatments consisted in eliciting beliefs about how other subjects chose in these same tables and repeating the first task once subjects learned how others have chosen in the first task. More information about the other tasks, together with complete instructions, can be found in Iriberri and Rey-Biel (2008a).

Throughout the experiment we ensured anonymity and effective separation of subjects. All subjects in the RU and RU+T sessions and only Deciders in the RC sessions made choices which determined the payoffs for both Deciders and Receivers, although both Deciders and Receivers were equally aware of the task and decision tables of the Deciders. Receivers in the RC sessions filled in a voluntary questionnaire that had no influence on their payoffs. 
All subjects were shown sequentially the same sixteen tables with three options describing the allocation of experimental units between two subjects, as illustrated in Figure 2.

Figure 2. Illustrative Decision Table

\begin{tabular}{|c|ccc|}
\hline & Selfish Action & Surplus Creating Action & Surplus Destroying Action \\
\hline Decider & $X$ & $x-1$ & $x-1$ \\
Receiver & $Y$ & $y+s$ & $y-s$ \\
\hline
\end{tabular}

One of the options contained the highest number of experimental units for the Decider. We will refer to this option as the selfish action. Another option was designed such that the Decider would lose one experimental unit in order to increase the Receiver's allocation in $s>1$ units (surplus creating action). The third option was designed such that the Decider would lose one experimental unit but now in order to decrease the Receiver's allocation in $s>1$ units (surplus destroying action). Different options were presented using neutral labels ("Option 1", “Option 2" and "Option 3") and we randomly varied the order among the selfish, surplus creating and surplus destroying actions from table to table, as shown in Figure 3. The sixteen tables differed in the number of created/destroyed units, $s$, and on whether the Decider was ahead (better-off than) or behind (worse-off than) the Receiver $(x>y$ or $x<y$ ). These variations allowed us the identification of different interdependent preferences-types.

\section{Figure 3. Sixteen Distribution Tables}

\begin{tabular}{|c|c|c|c|}
\hline $\begin{array}{c}\text { Table 1 } \\
(s=7)\end{array}$ & Option 1 & Option 2 & Option 3 \\
\hline Decider & 7 & 7 & 8 \\
\hline Receiver & 10 & 24 & 17 \\
\hline
\end{tabular}

\begin{tabular}{|c|c|c|c|}
\hline $\begin{array}{c}\text { Table 2 } \\
(s=5)\end{array}$ & Option 1 & Option 2 & Option 3 \\
\hline Decider & 16 & 17 & 16 \\
\hline Receiver & 3 & 8 & 13 \\
\hline
\end{tabular}

\begin{tabular}{|c|c|c|c|}
\hline $\begin{array}{c}\text { Table 3 } \\
(s=2)\end{array}$ & Option 1 & Option 2 & Option 3 \\
\hline Decider & 20 & 19 & 19 \\
\hline Receiver & 5 & 7 & 3 \\
\hline
\end{tabular}

\begin{tabular}{|c|c|c|c|}
\hline $\begin{array}{c}\text { Table 4 } \\
(s=7)\end{array}$ & Option 1 & Option 2 & Option 3 \\
\hline Decider & 10 & 10 & 11 \\
\hline Receiver & 21 & 7 & 14 \\
\hline
\end{tabular}

\begin{tabular}{|c|c|c|c|}
\hline $\begin{array}{c}\text { Table 5 } \\
(s=4)\end{array}$ & Option 1 & Option 2 & Option 3 \\
\hline Decider & 17 & 16 & 16 \\
\hline Receiver & 8 & 12 & 4 \\
\hline
\end{tabular}

\begin{tabular}{|c|c|c|c|}
\hline $\begin{array}{c}\text { Table 6 } \\
(s=3)\end{array}$ & Option 1 & Option 2 & Option 3 \\
\hline Decider & 8 & 7 & 7 \\
\hline Receiver & 17 & 14 & 20 \\
\hline
\end{tabular}

\begin{tabular}{|c|c|c|c|}
\hline $\begin{array}{c}\text { Table 7 } \\
(s=3)\end{array}$ & Option 1 & Option 2 & Option 3 \\
\hline Decider & 17 & 16 & 16 \\
\hline Receiver & 8 & 11 & 5 \\
\hline
\end{tabular}

\begin{tabular}{|c|c|c|c|}
\hline $\begin{array}{c}\text { Table 8 } \\
(s=5)\end{array}$ & Option 1 & Option 2 & Option 3 \\
\hline Decider & 8 & 7 & 7 \\
\hline Receiver & 17 & 12 & 22 \\
\hline
\end{tabular}

\begin{tabular}{|c|c|c|c|}
\hline $\begin{array}{c}\text { Table 9 } \\
(s=6)\end{array}$ & Option 1 & Option 2 & Option 3 \\
\hline Decider & 13 & 14 & 13 \\
\hline Receiver & 5 & 11 & 17 \\
\hline
\end{tabular}

\begin{tabular}{|c|c|c|c|}
\hline $\begin{array}{c}\text { Table 10 } \\
(s=4)\end{array}$ & Option 1 & Option 2 & Option 3 \\
\hline Decider & 4 & 5 & 4 \\
\hline Receiver & 24 & 20 & 16 \\
\hline
\end{tabular}




\begin{tabular}{|c|c|c|c|}
\hline $\begin{array}{c}\text { Table 11 } \\
(s=7)\end{array}$ & Option 1 & Option 2 & Option 3 \\
\hline Decider & 16 & 16 & 17 \\
\hline Receiver & 1 & 15 & 8 \\
\hline
\end{tabular}

\begin{tabular}{|c|c|c|c|}
\hline $\begin{array}{c}\text { Table 13 } \\
(s=2)\end{array}$ & Option 1 & Option 2 & Option 3 \\
\hline Decider & 4 & 4 & 5 \\
\hline Receiver & 22 & 18 & 20 \\
\hline
\end{tabular}

\begin{tabular}{|c|c|c|c|}
\hline $\begin{array}{c}\text { Table 15 } \\
(s=3)\end{array}$ & Option 1 & Option 2 & Option 3 \\
\hline Decider & 13 & 13 & 14 \\
\hline Receiver & 8 & 14 & 11 \\
\hline
\end{tabular}

\begin{tabular}{|c|c|c|c|}
\hline $\begin{array}{c}\text { Table 12 } \\
(s=4)\end{array}$ & Option 1 & Option 2 & Option 3 \\
\hline Decider & 20 & 19 & 19 \\
\hline Receiver & 5 & 1 & 9 \\
\hline
\end{tabular}

\begin{tabular}{|c|c|c|c|}
\hline $\begin{array}{c}\text { Table 14 } \\
(s=6)\end{array}$ & Option 1 & Option 2 & Option 3 \\
\hline Decider & 7 & 7 & 8 \\
\hline Receiver & 23 & 11 & 17 \\
\hline
\end{tabular}

\begin{tabular}{|c|c|c|c|}
\hline $\begin{array}{c}\text { Table 16 } \\
(s=5)\end{array}$ & Option 1 & Option 2 & Option 3 \\
\hline Decider & 10 & 10 & 11 \\
\hline Receiver & 19 & 9 & 14 \\
\hline
\end{tabular}

At the end of the experiment one decision table was randomly chosen to determine payments. ${ }^{7}$ All subjects received a 3 Euro participation fee. In the RU and RU+T sessions, subjects received the experimental units allocated to "Decider" in the randomly chosen table, in case they turned out to be Deciders and the experimental units allocated to "Receiver" by their randomly matched "Decider" in case they turned out to be Receivers. In the RC sessions Deciders received the experimental units they allocated to "Decider" in the randomly chosen table and their randomly matched Receiver got the units allocated to "Receiver".

\section{Results}

Table 1 reports the number of times each of the available actions, selfish, surplus creating and surplus destroying actions, were chosen in the RU, RU+T and RC treatments, separately for whether the Decider is originally ahead or behind the Receiver in terms of payoffs. It also shows the average play across subjects, as well as the frequency of play of each type of action.

We will first concentrate on the frequency of play for the selfish, surplus creating and surplus destroying actions. Two differences are most notable. First, the selfish action is the most frequently chosen in all decision tables under role certainty (RC), while the surplus creating action is the most chosen in all but one decision table in the RU treatment and in all but four tables in the RU+T treatment. In the eight tables in which the decider is ahead, the selfish action is most frequent in the $\mathrm{RC}$ treatment (66\%), while in the RU and RU+T treatments the surplus creating action was chosen

\footnotetext{
${ }^{7}$ Paying for one randomly chosen decision instead of paying for all the decisions has become a standard method in experimental economics and it may help avoiding wealth effects. Experimental work on testing for differences in behavior coming from paying for all decisions versus paying for a randomly chosen decision is limited. Hey and Lee (2005) test for this in the laboratory and they find that indeed subjects' behavior is not affected by whether subjects are paid for one randomly chosen decision instead of paying for all the decision tables.
} 
with highest frequency (69\% in RU and 64\% in RU+T). In the 8 tables where the decider is behind, again the selfish action is the most frequent under RC (72\%), while the surplus creating action is most frequent under RU (59\%). Selfish and surplus creating actions are balanced under RU+T. It is interesting to see that the inclusion of the understanding test increases the frequency of selfish actions when the decider is behind, although it is still far away from the frequency of selfish actions observed under RC. However, there are no differences in the frequency of surplus creating actions between the RU and RU+T treatments when the decider is ahead. Second, the surplus destroying action is barely chosen in the RU and RU+T treatments (1\% and $4 \%$ of the times, respectively) while it is chosen with low but positive frequency in the RC treatment, especially when the Decider is behind (11\%).

Pair-wise comparisons using Fisher exact probability test for the number of times each option is chosen in each of the 16 tables in the RU and RC treatments, and in the $\mathrm{RU}+\mathrm{T}$ and $\mathrm{RC}$ treatments, show statistical significant differences for all decision tables at the 5\% significance level. Pair-wise comparisons using Fisher exact probability comparing the RU and RU+T treatments do not show statistical significant differences in any but one of the 16 decision tables at the 5\% significance level (the exception is given by Table 15).

\begin{tabular}{|c|c|c|c|c|c|c|c|c|}
\hline \multicolumn{9}{|c|}{ Table 1. Actions With and Without Role Uncertainty } \\
\hline & & \multicolumn{3}{|c|}{$\begin{array}{c}\text { Decider's Position: Ahead } \\
\text { (8 Tables) }\end{array}$} & \multicolumn{3}{|c|}{$\begin{array}{c}\text { Decider's Position: Behind } \\
\text { (8 Tables) }\end{array}$} & \\
\hline & & $\begin{array}{l}\text { Selfish } \\
\text { Action }\end{array}$ & $\begin{array}{c}\text { Surplus } \\
\text { Creating } \\
\text { Action }\end{array}$ & $\begin{array}{l}\text { Surplus } \\
\text { Destroying } \\
\text { Action }\end{array}$ & $\begin{array}{l}\text { Selfish } \\
\text { Action }\end{array}$ & $\begin{array}{l}\text { Surplus } \\
\text { Creating } \\
\text { Action }\end{array}$ & $\begin{array}{l}\text { Surplus } \\
\text { Destroying } \\
\text { Action }\end{array}$ & TOTAL \\
\hline \multirow{4}{*}{$\begin{array}{c}\text { Role } \\
\text { Uncertainty } \\
(\text { RU) }\end{array}$} & $\begin{array}{c}\text { Number } \\
\text { of Actions }\end{array}$ & 191 & 443 & 6 & 251 & 375 & 14 & 1280 \\
\hline & $\begin{array}{l}\text { Average } \\
\text { across } \\
\text { Subjects }\end{array}$ & 2.39 & 5.54 & 0.08 & 3.14 & 4.69 & 0.18 & 16 \\
\hline & Stand. Dev. & $(3.23)$ & $(3.23)$ & $(0.35)$ & $(2.88)$ & $(2.99)$ & $(0.71)$ & -- \\
\hline & $\begin{array}{l}\text { Frequency of } \\
\text { Play }\end{array}$ & 0.30 & 0.69 & 0.01 & 0.39 & 0.59 & 0.02 & 1 \\
\hline \multirow{4}{*}{$\begin{array}{c}\text { Role } \\
\text { Uncertainty } \\
\text { and } \\
\text { Understanding } \\
\text { Test } \\
(\mathbf{R U + T})\end{array}$} & $\begin{array}{l}\text { Number } \\
\text { of Actions }\end{array}$ & 145 & 286 & 17 & 214 & 213 & 21 & 896 \\
\hline & $\begin{array}{l}\text { Average } \\
\text { across } \\
\text { Subjects }\end{array}$ & 2.59 & 5.11 & 0.3 & 3.82 & 3.8 & 0.38 & 16 \\
\hline & Stand. Dev. & $(2.49)$ & $(2.66)$ & $(0.53)$ & $(2.54)$ & $(2.67)$ & $(0.66)$ & -- \\
\hline & $\begin{array}{l}\text { Frequency of } \\
\text { Play }\end{array}$ & 0.32 & 0.64 & 0.04 & 0.48 & 0.48 & 0.05 & \begin{tabular}{l|l}
1 & 1 \\
\end{tabular} \\
\hline & $\begin{array}{l}\text { Number } \\
\text { of Actions }\end{array}$ & 316 & 142 & 22 & 346 & 80 & 54 & \multirow[t]{2}{*}{960} \\
\hline Role & Average & 5.27 & & 0.37 & 5.77 & 1.33 & 0.90 & \\
\hline
\end{tabular}




\begin{tabular}{|c|c|c|c|c|c|c|c|c|c|}
\hline \multirow[t]{3}{*}{$\begin{array}{l}\text { Certainty } \\
\text { (CR) }\end{array}$} & $\begin{array}{c}\text { across } \\
\text { Subjects }\end{array}$ & & 2.37 & & & & & \multicolumn{2}{|c|}{16} \\
\hline & Stand. Dev. & (2.79) & $(2.65)$ & (1.13) & (2.54) & $(2.17)$ & $(1.90)$ & & \\
\hline & $\begin{array}{c}\text { Frequency of } \\
\text { Play }\end{array}$ & 0.66 & 0.30 & 0.05 & 0.72 & 0.17 & 0.11 & 1 & 1 \\
\hline
\end{tabular}

We now show the classification of subjects into four different preferences-types, Selfish (SF), Social Welfare maximizing (SW), Inequity Averse (IA) and Competitive (CP). The identification strategy for the preferences-types classification is based on Charness and Rabin's (2002) piece-wise linear utility function, shown in equation (1). Deciders' utility $\left(u_{D}\right)$ depends on both Decider's own payoff $\left(\pi_{D}\right)$ and Receiver's payoff $\left(\pi_{R}\right)$. The two key parameters are the weight on the Receiver's payoff, $\rho$, when the Decider is ahead of the Receiver $\left(\pi_{D}>\pi_{R}\right)$ and, the weight, $\sigma$, when the Decider is behind the Receiver $\left(\pi_{R}>\pi_{D}\right)$.

(1) $u_{D}\left(\pi_{R}, \pi_{D}\right)=(\rho r+\sigma s) \pi_{R}+(1-\rho r-\sigma s) \pi_{D}$

where $r=1$ if $\pi_{D}>\pi_{R}$, and $r=0$ otherwise, and $s=1$ if $\pi_{D}<\pi_{R}$, and $s=0$ otherwise.

Each Decider $i$ at decision table $t$, has three available actions, $a=\{S, C, D\}$, referring to selfish, surplus creating and surplus destroying actions respectively. Notice that SF Deciders should always choose the selfish action. SW Deciders should choose either the surplus creating or the selfish action regardless of their relative position and depending on the value of $s$. IA Deciders should choose either the surplus creating or the selfish action when ahead, but either the selfish or the surplus destroying action when behind. Finally, CP Deciders should choose either the surplus destroying or the selfish action, regardless of their relative position and again depending on the value of $s$. We also allow individuals to make uniform iid errors, $\varepsilon$, which implies that with probability $\varepsilon$ each available action will be taken with equal probability. Notice that errors include two types of behavior. The most severe type of mistake consists of choosing an action not compatible with the estimated preferences type. For example, choosing a surplus destroying (creating) action for a subject whose preferences are of the type SW (CP). The less severe mistake consists in choosing a costly action at some price, but not choosing it at lower price. For example, choosing to create surplus when $s=2$ but not when $s=7$. 
Our econometric specification follows a mixture-of-types model as explained in detail in Iriberri and Rey-Biel (2008a). Based on Charness and Rabin's (2002) piecewise linear utility function, a preferences-type $k$, where we consider the four different types described above, will be defined by the sign the parameters $\rho$ and $\sigma$ may take. We estimate a triple $(\rho, \sigma, \varepsilon)$ for each individual $i$ and classify subjects according to the sign of these parameters. If $\rho$ and $\sigma$ are both consistent with being zero then this subject will be classified under SF preferences type. If $\rho$ and $\sigma$ are both estimated to be strictly greater than zero then this subject will be classified under SW preferences type. If $\rho$ is estimated to be greater than zero and $\sigma$ is estimated to be strictly smaller or equal to zero then this subject will be classified under IA preferences type. Finally, if $\rho$ and $\sigma$ are both estimated to be negative or $\rho$ is estimated to be zero but $\sigma$ is estimated to be strictly negative then this subject will be classified under CP preferences type. After this estimation we calculate the preferences-type distribution $\left(p_{k}\right)$ for the treatments with and without role uncertainty, shown in Table 2. Some subjects were estimated within an interdependent preferences type with a high level of noise $(\hat{\varepsilon}>0.38)$, or their type was not clear ( $\rho$ and $\sigma$ accepted a range of possible values that made impossible a unique classification). We excluded those subjects from this classification, such that we are left with 70 subjects out of 80 for RU, 44 subjects out of 56 for RU+T treatment and 52 out of 60 subjects for RC. Yet, we were able to classify with this method between $79 \%$ and $88 \%$ of the subjects. Table 2 also shows the estimation of parameters for each preferences-type averaged across subjects within the type.

\begin{tabular}{|c|c|c|c|c|c|c|c|c|c|c|c|c|}
\hline \multicolumn{13}{|c|}{$\begin{array}{c}\text { Table 2. Interdependent Preferences-Type Distribution } \\
\text { With and Without Role Uncertainty }\end{array}$} \\
\hline & \multicolumn{4}{|c|}{ Role Uncertainty (RU) } & \multicolumn{4}{|c|}{$\begin{array}{c}\text { Role Uncertainty with } \\
\text { Understanding Test } \\
\text { (RU+T) }\end{array}$} & \multicolumn{4}{|c|}{ Role Uncertainty (RC) } \\
\hline & $p_{k}$ & $\overline{\rho_{k}}$ & $\overline{\sigma_{k}}$ & $\overline{\varepsilon_{k}}$ & $p_{k}$ & $\overline{\rho_{k}}$ & $\overline{\bar{\sigma}_{k}}$ & $\overline{\bar{\varepsilon}_{k}}$ & $p_{k}$ & $\overline{\rho_{k}}$ & $\overline{\sigma_{k}}$ & $\overline{\varepsilon_{k}}$ \\
\hline SF & 0.21 & --- & -- & 0.04 & 0.20 & -- & --- & 0.00 & 0.44 & -- & -- & 0.03 \\
\hline SW & $\mathbf{0 . 7 4}$ & 0.33 & 0.29 & 0.11 & 0.64 & 0.31 & 0.27 & 0.11 & 0.21 & 0.25 & 0.21 & 0.18 \\
\hline IA & 0.04 & 0.25 & 0.00 & 0.16 & 0.14 & 0.33 & -0.09 & 0.17 & 0.25 & 0.24 & -0.16 & 0.21 \\
\hline $\mathrm{CP}$ & $\mathbf{0}$ & -- & -- & -- & 0.02 & -1.01 & -0.51 & 0.28 & 0.10 & -0.34 & -0.38 & 0.07 \\
\hline Log Likelihood & \multicolumn{4}{|c|}{-261.11} & \multicolumn{4}{|c|}{-164.27} & \multicolumn{4}{|c|}{-217.99} \\
\hline
\end{tabular}

We now focus on the preferences-type distribution shown in bold in Table 2 . Consistent with the analysis of the frequency of actions, the preferences-type distribution is significantly affected with the use of role uncertainty. In the role 
uncertainty treatments the most frequent type is $\mathrm{SW}$ (74\% in RU and 64\% in RU+T), followed by SF (21\% in RU and $20 \%$ in RU+T), while few subjects are classified as IA and $\mathrm{CP}$ (4\% in RU and $14 \%$ in RU+T for IA, and $0 \%$ in RU and $2 \%$ in RU+T for CP). On the other hand, in the RC treatment, SF type was the most frequent type (44\%), followed by IA and SW with similar proportions (25\% and $21 \%$ respectively). Finally, $10 \%$ of the subjects were classified as CP.

We conclude that the use of role uncertainty leads to different individual behaviour when compared to behaviour using role certainty in modified dictator games. Furthermore, this difference is not due to the poor understanding of instructions regarding the payoff mechanism under role uncertainty. The treatment which includes this understanding test shows similar results, showing again significant differences compared to behaviour under role certainty. All subjects included in the analysis did pass the understanding test, such that we can rule out that the instructions regarding the payoff mechanism under role uncertainty were incorrectly understood.

In light of our results, we now discuss the findings of Charness and Grosskopf (2001) and Engelmann and Strobel (2004).

Charness and Grosskopf (2001) use role uncertainty in their Study 2 where subjects make three decisions, shown in Figure 4. In Decision 1, subjects choose between a selfish action (B1) and a costly surplus creating action (B2) and they find that B2 is chosen with the highest frequency $(66.7 \%)$. In Decision 2, subjects choose between a selfish and at the same time costly surplus creating action and an equal payoff distribution. They find that B1 is chosen with highest frequency (88\%). Finally, in Decision 3, subjects choose between a selfish and a surplus creating action which involves no cost, that is, both actions yield the same payoff for the decider. They find that the large majority $(74.1 \%)$ chooses to create the maximum possible quantity $(x=1200)$. While our results do not imply that there would be any change in the frequencies observed in decisions 2 and 3 had role certainty been used since deviating from the selfish action implies no cost for the decider (and it is actually profitable in Decision 2), they do imply that the high prevalence of surplus creating actions (B2) found in Decision 1 may be driven by the use of role uncertainty. ${ }^{8}$

\footnotetext{
${ }^{8}$ Choosing the surplus creating action when it involves no cost for the Decider is consistent with a preferences type proposed by Fisman et al. (2007) called lexicographic self. We cannot separate this type from other preferences types so our results have no implications for the decision tables that present such choices.
} 
Figure 4. Decision Tables in Study 2 in Charness and Grosskopf (2001)

\begin{tabular}{|c|c|c|c|c|c|c|}
\hline & \multicolumn{2}{|c|}{ Decision 1 } & \multicolumn{2}{c|}{ Decision 2 } & \multicolumn{2}{c|}{ Decision 3 } \\
\hline & B1 & B2 & B1 & B2 & B1 & B2 \\
\hline Decider & $\mathbf{6 2 5}$ & $\mathbf{6 0 0}$ & 625 & 600 & 600 & 600 \\
Receiver & $\mathbf{6 2 5}$ & $\mathbf{1 2 0 0}$ & 1200 & 600 & 600 & $300 \leq x \leq 1200$ \\
\hline Choice & $\mathbf{3 3 . 3 \%}$ & $\mathbf{6 6 . 7 \%}$ & $88 \%$ & $12 \%$ & \multicolumn{2}{c|}{$74.1 \% \mathrm{x}=1200$} \\
\hline
\end{tabular}

Engelmann and Strobel (2004) design 3-player modified dictator games, which aim to distinguish between two types of inequity aversion preferences, those proposed by Fehr and Schmidt (1999) and those by Bolton and Ockenfels (2000), as well as to separate inequity aversion preferences from efficiency and maximin motives, very close in spirit to SW maximizing preferences. Figure 5 includes their three sets of distributional games. The first and third sets of games have the property that the decision maker gets exactly the same payoff no matter her chosen action and thus, there is no cost for the decider when choosing surplus creating or destroying action (see footnote 9). Among the second set of games, only games $\mathrm{Ny}$ and Nyi separate between the selfish (C) and the costly surplus creating actions (A). The authors find that the most frequent choice is that of surplus creating action and not the selfish action, in both $\mathrm{Ny}$ (76.7\% vs. $10 \%)$ and Nyi (60\% vs. $23.3 \%)$. Our results imply that the high frequency of surplus creating choices in these two tables may be driven by the use of role uncertainty. Engelmann and Strobel (2004) included, unlike Charness and Grosskopf (2001), control treatments replicating some of their tables with role certainty. Unfortunately for our research purposes, their robustness check was only done for tables in which the Decider's payments are not affected by her choice (table Ex from set 1 and table P from set 3), while our results imply that the affected decision tables would be Ny and Nyi. ${ }^{9}$

Figure 5. Decision Tables in Engelmann and Strobel (2004)

\begin{tabular}{|c|c|c|c|c|c|c|c|c|c|c|c|c|}
\hline & \multicolumn{3}{|c|}{ F } & \multicolumn{3}{|c|}{ E } & \multicolumn{3}{|c|}{ Fx } & \multicolumn{3}{|c|}{ Ex } \\
\hline & $\mathrm{A}$ & $\mathrm{B}$ & $\mathrm{C}$ & $\mathrm{A}$ & $\mathrm{B}$ & $\mathrm{C}$ & $\mathrm{A}$ & $\mathrm{B}$ & $\mathrm{C}$ & $\mathrm{A}$ & $\mathrm{B}$ & $\mathrm{C}$ \\
\hline Receiver 1 & 8.2 & 8.8 & 9.4 & 9.4 & 8.4 & 7.4 & 17 & 18 & 19 & 21 & 17 & 13 \\
\hline Decider & 5.6 & 5.6 & 5.6 & 6.4 & 6.4 & 6.4 & 10 & 10 & 10 & 12 & 12 & 12 \\
\hline Receiver 2 & 4.6 & 3.6 & 2.6 & 2.6 & 3.2 & 3.8 & 9 & 5 & 1 & 3 & 4 & 5 \\
\hline Freq. Choice & $83.8 \%$ & $10.3 \%$ & $5.9 \%$ & $39.7 \%$ & $23.5 \%$ & $36.7 \%$ & $86.7 \%$ & $6.7 \%$ & $6.7 \%$ & $40 \%$ & $16.7 \%$ & $43.3 \%$ \\
\hline
\end{tabular}

\footnotetext{
${ }^{9}$ Notice that Engelmann and Strobel's (2004) tables involve three players, while our tables only involve two players. This is important since it is not clear how the veil of ignorance line of reasoning, which we believe is the source of the confusion, would differ between two-player and three-player games when the decider's payoffs are kept constant independently of the chosen action.
} 


\begin{tabular}{|c|c|c|c|c|c|c|c|c|c|c|c|c|}
\hline & \multicolumn{4}{|c|}{ N } & \multicolumn{3}{|c|}{ Nx } & \multicolumn{3}{|c|}{ Ny } & \multicolumn{3}{|c|}{ Nyi } \\
\hline & $\mathrm{A}$ & $\mathrm{B}$ & $\mathrm{C}$ & $\mathrm{A}$ & $\mathrm{B}$ & $\mathrm{C}$ & $\mathbf{A}$ & $\mathbf{B}$ & $\mathbf{C}$ & $\mathbf{A}$ & $\mathbf{B}$ & $\mathbf{C}$ \\
\hline Receiver 1 & 16 & 13 & 10 & 16 & 13 & 10 & $\mathbf{1 6}$ & $\mathbf{1 3}$ & $\mathbf{1 0}$ & $\mathbf{1 6}$ & $\mathbf{1 3}$ & $\mathbf{1 0}$ \\
\hline Decider & 8 & 8 & 8 & 9 & 8 & 7 & $\mathbf{7}$ & $\mathbf{8}$ & $\mathbf{9}$ & $\mathbf{7 . 5}$ & $\mathbf{8}$ & $\mathbf{8 . 5}$ \\
\hline Receiver 2 & 5 & 3 & 1 & 5 & 3 & 1 & $\mathbf{5}$ & $\mathbf{3}$ & $\mathbf{1}$ & $\mathbf{5}$ & $\mathbf{3}$ & $\mathbf{1}$ \\
\hline $\begin{array}{c}\text { Freq. } \\
\text { Choice }\end{array}$ & $70 \%$ & $26.7 \%$ & $3.3 \%$ & $83.3 \%$ & $13.3 \%$ & $3.3 \%$ & $\mathbf{7 6 . 7 \%}$ & $\mathbf{1 3 . 3} \%$ & $\mathbf{1 0 \%}$ & $\mathbf{6 0 \%}$ & $\mathbf{1 6 . 7 \%}$ & $\mathbf{2 3 . 3 \%}$ \\
\hline
\end{tabular}

\begin{tabular}{|c|c|c|c|c|c|c|c|c|c|}
\hline & \multicolumn{3}{|c|}{ R } & \multicolumn{3}{c|}{ P } & \multicolumn{3}{c|}{ Ey } \\
\hline & $\mathrm{A}$ & $\mathrm{B}$ & $\mathrm{C}$ & $\mathrm{A}$ & $\mathrm{B}$ & $\mathrm{C}$ & $\mathrm{A}$ & $\mathrm{B}$ & $\mathrm{C}$ \\
\hline Receiver 1 & 11 & 8 & 5 & 14 & 11 & 8 & 21 & 17 & 13 \\
\hline Decider & 12 & 12 & 12 & 4 & 4 & 4 & 9 & 9 & 9 \\
\hline Receiver 2 & 2 & 3 & 4 & 5 & 6 & 7 & 3 & 4 & 5 \\
\hline Freq. Choice & $26.7 \%$ & $20 \%$ & $53.3 \%$ & $60 \%$ & $6.7 \%$ & $33.3 \%$ & $40 \%$ & $23.3 \%$ & $36.7 \%$ \\
\hline
\end{tabular}

Our results do not invalidate in any way the general results found in Charness and Grosskopf (2001) and Engelmann and Strobel (2004), because they only affect a very limited subset of the games they use (1 out of 3 in Charness and Grosskopf, 2001, and 2 out of 11 in Engelmann and Strobel, 2004). Also, we have to be careful in exporting our results to theirs. Their instructions were different from ours in important details such as the inclusion of examples and the understanding test, which always raises question about the external validity of our results to their experiments. However, our results definitely warn against the use of role uncertainty in future experimental designs aiming to identify different motives behind non-selfish behavior.

\section{Conclusion}

We find that role uncertainty exacerbates the presence of altruistic behavior and dissipates the presence of selfish and spiteful behavior in a simple modified dictator games experiment aimed to identify interdependent preferences types. This method yields a preferences-type distribution with a significant upward bias on the frequency of Social Welfare maximizing preferences and a significant downward bias on the estimation of the frequencies of Selfish, Inequity Averse and Competitive preferences.

A control treatment with role uncertainty, but in which subjects performed an understanding test prior to the experiment, shows a similar pattern in behavior to that of role uncertainty and no understanding test. Given this result and the fact that almost all subjects in the RU+T treatment passed the understanding test, we conclude that the higher frequency of welfare maximizing behavior under role uncertainty is not due to subjects not understanding the payoff mechanism under role uncertainty in the instructions. We conclude that, although subjects did understand the payment procedure 
under role uncertainty there is something inherent to the role uncertainty procedure that makes them choose differently than under role certainty.

In line with Camerer (2003), Smith (2008) and Cox (2010), who highlight the fragility of dictator game experimental results to procedural changes, further research on whether and when cost-saving experimental methods affect conclusions obtained in experiments is thus warranted.

\section{References}

Andreoni, J., Miller, J., (2002). "Giving According to GARP: An Experimental Test of the Consistency of Preferences for Altruism”. Econometrica, 70, 737 - 753.

Andreoni, J., Castillo, M., Petrie, R., (2003). "What Do Bargainers' Preferences Look Like? Experiments with a Convex Ultimatum Game". American Economic Review 93, 672-685.

Bolton, G., Ockenfels, A., (2000). "ERC: A Theory of Equity, Reciprocity and Competition". The American Economic Review 90(1), 166-193.

Bolton, G., Ockenfels, A., (2006). "Inequality Aversion, Efficiency, and Maximin Preferences in Simple Distribution Experiments: Comment". The American Economic Review 96(5), 1906-1911.

Brandts, J., Charness, G., (2009). "The Strategy Method: A Survey of Experimental Evidence". Mimeo.

Burks, S., Carpenter, J., Verhoogen, E., (2003). "Playing Both Roles in the Trust Game". Journal of Economic Behavior and organization 51, 195-216.

Camerer, C. (2003). Behavioral Game Theory. Experiments in strategic Interaction. Princeton University Press.

Charness, G., Grosskopf, B., (2001). "Relative Payoffs and Happiness: an Experimental Study". Journal of Economic Behavior and Organization, 45, 301-328.

Charness, G., Rabin, M., (2002). "Understanding Interdependent With Simple Tests". The Quarterly Journal of Economics, 117(3), 817-869.

Cox, J. (2010). "Some Issues of Methods, Theories, and Experimental Designs". Journal of Economic Behavior and Organization, 73(1), 24-28.

Engelmann, D., Strobel, M., (2004). "Inequality Aversion, Efficiency, and Maximin Preferences in Simple Distribution Experiments". The American Economic Review 94(4), 857-869.

Fehr, E., Schmidt, K. M. (1999). "A theory of fairness, competition, and cooperation". The Quarterly Journal of Economics 114: 817-868. 
Fischbacher, U., (2007). "Z-Tree: Zurich Toolbox for Ready-made Economic Experiments". Experimental Economics 10(2), 171-178.

Fisman, R., Kariv, S., Markovits, D. (2007). "Individual Preferences for Giving". The American Economic Review, 97, 2, 153-158.

Greiner, B. (2004). "The Online Recruitment System ORSEE 2.0 - A Guide for the Organization of Experiments in Economics". University of Cologne WP Series in Economics 10, 2004.

Harsanyi, J. (1953). "Cardinal Utility in Welfare Economics and in the Theory of Risk-Taking", Journal of Political Economy 61(5):434-5

Hey, J., Lee, J. (2005). “Do Subjects Separate or Are They Sophisticated?”. Experimental Economics 8, 233-345.

Iriberri, N., Rey-Biel, P. (2008a). "Elicited Beliefs and Social Information in Modified Dictator Games: What Do Dictators Believe Other Dictators Do?" UPF Working Papers Series N. 1137.

Rawls, J. (1971). A Theory of Justice. Cambridge: Harvard University Press.

Roth, A. (1995). "Bargaining Experiments." In J. Kagel and A. Roth (eds.), Handbook of Experimental Economics, 253-348.

Selten, R. (1967). "Die Strategiemethode zur Erforschung des Eingeschränt Rationalen Verhaltens im Rahmen eines Oligopolexperiments." In H. Sauermann, (ed.). Beiträge zur Experimentellen Wirtschaftsforscgung, 136-168.

Smith, Vernon L. (2008). "Theory and Experiment: What are the Questions?", Journal of Economic Behavior and Organization, (forthcoming).

\section{Appendix: Instructions.}

Below you can find a translation of the experimental instructions which were handed to all subjects in the treatments with Role Uncertainty (RU and RU+T) and to Deciders in the treatment with Role Certainty (RC). Instructions in treatments RU and RU+T were identical, apart from omitting any reference to "Parts 2 and 3 of the experiment" in the instructions for the RU+T treatment. A summary of instructions appeared on subjects' screens before each part. Complete instructions for the other two tasks subjects did in Part 2 and Part 3 of the RU and RC treatments can be found in Iriberri and Rey-Biel (2008a). Before starting the experiment, participants in the RU+T treatment answered the understanding test, which is reproduced in section 6.2.

\subsection{Instructions with Role Uncertainty (RU and RU+T)}

\section{THANK YOU FOR PARTICIPATING IN OUR EXPERIMENT!}

This is an experiment and thus, no talking, looking-around or walking is allowed. If you have any question or need help please raise your hand and one of the researchers will assist you. If you do not 
This experiment is about individual decisions. Both Pompeu Fabra and Autònoma de Barcelona universities have provided funds to carry it out. You will receive 3 euros for having arrived on time. Additionally, if you follow the instructions correctly you may earn more money. This additional money will be determined by your choices, by choices of other participants in the experiment and also by chance.

The experiment has three parts. Before each part, we will let you know about the tasks as well as about how your decisions and those made by other participants will affect your payments.

[Authors' note to readers: The previous paragraph was omitted in the $R U+T$ treatment]

Everything you earn will be for you and paid in cash inside a closed envelope in a strictly private way at the end of the experimental session.

Each participant has a strictly confidential "Experiment Code" to guarantee that no participant can identify another one by his/her decisions nor earnings. Researchers will observe each participant's earnings at the end of the experiment but we will not associate your decisions with any participants' names.

Your Experiment Code is: $\mathrm{XX}$

The experiment consists of three parts. Your final payment will be the sum of a participation fee of the 3 euros plus whatever you earn in the three parts of the experiment.

[Authors' note to readers: The previous paragraph was omitted in the $R U+T$ treatment]

Each experimental point corresponds to 25 Euro cents.

Thus, if you obtain a total of 32 points, you will receive a total of 11 euros ( 3 for participating and 8 from converting 32 experimental points into euros at a rate of 4 experimental point $* 0.25$ = 1 Euro).

If, for example, you obtain 10 experimental points, you will receive 5.5 Euros $(10 * 0.25=2.5+3$ =5.5).

If, for example, you obtain 70 experimental points, you will receive 20.5 Euros $(70 * 0.25=17.5+$ $3=20.5$ ).

[Authors' note to readers: The following three sentences are relevant only for Parts 2 and 3 while this paper focuses exclusively on the results in Part 1]

The 20 participants have been randomly divided into two groups of 10 subjects each: "group A" and "group B". You belong to Group X.

All participants in the experiment will do the same 3 PARTS.

PART 1 is about to start. Please wait until everyone has read these instructions to read the instructions for PART 1.

\section{Instructions for Deciders' Task 1}

PART 1

In this part of the experiment we are going to show you 16 tables. The 16 tables the computer will show you will look as follows:

\begin{tabular}{|c|ccc|}
\hline & Option 1 & Option 2 & Option 3 \\
\hline Decider & 8 & 4 & 11 \\
Receiver & 17 & 19 & 23 \\
\hline
\end{tabular}


In each of the tables you must choose between "Option 1", "Option 2" and "Option 3". Each of these 3 options describes how many experimental points a participant ("Decider") receives and how many another randomly matched participant ("Receiver") gets.

For each of the 16 tables you will be randomly matched with a different participant from your group. At no time a participant will know who they are matched with in any table.

[Authors' note to readers: in RU+T the instructions said: For each of the 16 tables you will be randomly matched with a different participant from this session.]

When the experiment is over, the computer will randomly choose one of the 16 tables to determine the payments for PART 1. The computer will also randomly choose whether you are the "Decider" or the "Receiver". That is, the computer will randomly choose if the option you have chosen in that particular table is implemented, so that you will be the "Decider" or, on the other hand, if the option chosen by the participant from your group with whom you are randomly matched in that particular table is implemented.

In the case the computer assigns your option to be implemented you will receive the amount of experimental points corresponding to "Decider" in the chosen table and your matched participant will receive the number of experimental points corresponding to "Receiver" in the same table.

For example, if the chosen table was the one that appears above, the computer determined that your option is the one to be implemented, and you had chosen "Option 2", you would obtain 4 experimental points while your matched participant would obtain 19 experimental points.

If, on the other hand, the chosen table was the one that appears above, the computer determined that the option chosen by your matched participant is the one to be implemented, and such participant had chosen "Option 1", you would obtain 17 experimental points while your matched participant would obtain 8 experimental points.

Notice that the numbers in the example are just for illustrative purposes. They DO NOT intend to suggest how anyone may choose among the different options.

Please notice that chance uniquely determines whether your role will be "Decider" or "Receiver", once all participants have made their choices. Thus, the option you choose will only be taken into account if chance finally determines that for a particular table it is your option the one being implemented. In case in the chosen table your choice is not the one being implemented, your choice is simply not taken into account and no participant is informed of it. Therefore, in case your choice is not being implemented, your choice can affect in no way neither your payment nor the payments of any other participant.

Once you have chosen your option in a particular table, please press "OK" and wait for the other participants to make their choice before moving to the next table.

\subsection{Understanding test taken by participants in the role uncertainty treatment with test $(\mathbf{R U}+\mathrm{T})$}

Before starting, and in order to make sure that you have understood the instructions, we ask you to fill in the following two examples. Please use the following table to answer.

\begin{tabular}{|c|ccc|}
\hline & Option 1 & Option 2 & Option 3 \\
\hline Decider & 2 & 10 & 8 \\
Receiver & 15 & 8 & 6 \\
\hline
\end{tabular}

1. The chosen table was the one that appears above. Assume you have chosen "Option 2" and your matched participant has chosen "Option 1". The computer determines that your option is the one to be implemented. Then you would obtain _ experimental points and your matched participant would obtain __ experimental points. 
2. The chosen table was the one that appears above. Assume you have chosen "Option 1" and your matched participant has chosen "Option 3". The computer determines that the option chosen by your matched participant is the one to be implemented. Then you would obtain __ experimental points and your matched participant would obtain __ experimental points.

[Authors' note to readers: the correct answers are 6 and 8, respectively]

Please wait until we check your answers to make sure that you have understood the instructions. Once we have checked all answers, you will be able to start the experiment on the computer screen.

Remember that in the experiment once you have chosen your option in a particular table, you must press "OK" and wait for the other participants to make their choice before moving to the next table.

\subsection{Instructions without Role Uncertainty (RC)}

THANK YOU FOR PARTICIPATING IN OUR EXPERIMENT!

This is an experiment and thus, no talking, looking-around or walking is allowed. If you have any question or need help please raise your hand and one of the researchers will assist you. If you do not follow the indicated rules, WE WILL ASK YOU TO LEAVE THE EXPERIMENT AND YOU WILL NOT RECEIVE ANY PAYMENT. Thank you.

This experiment is about individual decisions. Both Pompeu Fabra and Autònoma de Barcelona universities have provided funds to carry it out. You will receive 3 euros for having arrived on time. Additionally, if you follow the instructions correctly you may earn more money.

The experiment has three parts. Before each part, we will let you know about the tasks you have to do and how your decisions will affect your payments. Everything you earn will be for you and paid in cash inside a closed envelope in a strictly private way at the end of the experimental session.

Each participant has a strictly confidential "Experiment Code" to guarantee that no participant can identify another one by his/her decisions nor earnings. Researchers will observe each participant's earnings at the end of the experiment but we will not associate your decisions with any participants' names.

Your Experiment Code is: $\mathrm{XX}$

The experiment consists of three parts. Your final payment will be the sum of a participation fee of the 3 euros plus whatever you earn in the three parts of the experiment.

Each experimental point corresponds to 25 Euro cents.

Thus, if you obtain a total of 32 points, you will receive a total of 11 euros ( 3 for participating and 8 from converting 32 experimental points into euros at a rate of 4 experimental point $* 0.25$ $=1$ Euro).

If, for example, you obtain 10 experimental points, you will receive 5.5 Euros $(10 * 0.25=2.5+3$ =5.5).

If, for example, you obtain 70 experimental points, you will receive 20.5 Euros $(70 * 0.25=17.5+$ 3 = 20.5).

There are 40 participants in this experiment, 20 in the laboratory to whom we refer to as "Deciders" and 20 in a classroom to whom we refer to as "Receivers".

As you have observed, who is a "Decider" (and stayed in the laboratory) and who is a "Receiver" (and went to the classroom) has been randomly decided by extracting a paper from a bag. 
"Deciders" take decisions which affect their payments and the payments of other participants in the experiment. "Receivers" do not take any decision, which affect neither their payments nor those of other participants in the experiment. When the experiment concludes, we will first pay "Deciders" in private. Once "Deciders" have left, "Receivers" will come to the laboratory and will be paid in private.

[Authors' note to readers: The following two sentences are relevant only for Parts 2 and 3 while this paper focuses exclusively on the results in Part 1]

The 20 "Deciders" have been divided in two groups of 10 subjects each: "group A" and "group B". You belong to Group X. If you are a "Receiver" you do not belong to any group.

PART 1 is about to start. Please wait until everyone has read the instructions for PART 1.

\section{Instructions for Deciders' Task 1}

\section{PART 1}

In this part of the experiment we are going to show you 16 tables. The 16 tables the computer will show you will look as follows:

\begin{tabular}{|c|ccc|}
\hline & Option 1 & Option 2 & Option 3 \\
\hline Decider & 8 & 7 & 11 \\
Receiver & 17 & 19 & 13 \\
\hline
\end{tabular}

In each of the tables you must choose between "Option 1", "Option 2" and "Option 3". Each of these 3 options describes how many experimental points a participant ("Decider") receives and how many another randomly matched participant ("Receiver") gets.

At no time a participant will know who they are matched with in any table.

When the experiment is over, the computer will randomly choose one of the 16 tables to determine the payments for PART 1.

You will receive the amount of experimental points corresponding to "Decider" in the chosen table and your matched participant will receive the number of experimental points corresponding to "Receiver" in the same table.

For example, if the chosen table was the one that appears above and you had chosen "Option 2", you would obtain 7 experimental points while your matched participant would obtain 19 experimental points.

Notice that the numbers in the example are just for illustrative purposes. They DO NOT intend to suggest how anyone may choose among the different options.

Participants in the other classroom ("Receivers") can not take any decision which may affect your payments or their payments.

What you earn and what your matched participant ("Receiver") earns depends only on your decisions and on the randomly chosen table.

Once you have chosen your option in a particular table, please press "OK" and wait for the other participants to make their choice before moving to the next table.

\subsection{Anonymous Questionnaire filled by all participants in all treatments:}

[Authors' note to readers: In the $R U+T$ treatment, questions 2 and 3 did not make any reference to other parts.] 
1. What do you think about the experiment?

2. How have you made your choices in each part of the experiment?

3. How do you think others have made their choices in each part of the experiment?

4. Are you satisfied with your earnings in the experiment?

5. Gender.

6. Age.

7. What are you studying?

8. Would you like to add any other comment? 